CLIMATOLOGIA AGRICOLA DE LA COMARCA DE ZARAGOZA

\author{
Maria Lu\% HERNANDEZ NAVARRO. \\ Universidad de Zaragoza
}

\title{
INTRODUCCION
}

Las actividades humanas conviven estrechamente relacionadas con el medio en el que se desenvuelven.

Desde siempre la agricultura ha sufrido una acomodación progresiva a las condiciones bióticas y abióticas (edáficas, climáticas y técnicas). Y, a pesar de los progresos científicos y de la capacidad humana para transformar y amortiguar los elementos desfavorables del medio, que ha abierto innumerables posibilidades al quehacer agrícola, el clima, en nuestro caso, sigue ejerciendo una importante influencia sobre la toma de decisiones en el cultivo de especies, variedades y el cmpleo de métodos de trabajo.

Esta conexión real entre el clima y la agricultura es la base de partida de la investigación agroclimática, cuyos principales objctivos son :

- conocer el comportamiento del clima, considerando sus elementos (precipitaciones, humedad, temperaturas, insolación, vientos, balance hidrico) y las interrelaciones que existen entre ellos. agricultura. -estudiar las posibilidades y limitaciones que éste aporta a la -servir de ayuda y apoyo al desarrollo y optimización de la producción agrícola y apuntar las bases científicas que constituyan la base de la planificación agrícola y de la Organización del Territorio que, en armonía con el entorno bioclimático, consiga una mayor disponibilidad de las potencialidades existentes.

Realzando la vocación espacial de la Ordenación del territorio, y de las actividades agrícolas, en concrcto, centraremos este análisis agroclimático en el sector central de la Depresión del Ebro, al que hemos denominado, aunque no lo sea estrictamente, "Comarca de Zaragoza" y que abarca el sector central de la Depresión, parte del piedemonte de la cordillera lbérica zaragozana y el tramo inferior del valle del Gállego.

Constituye un área deprimida cntre dos importantes cordilleras: el Sistema lbćrico y los Pirincos.

La mayor parte del territorio se reparte entre los $200-400 \mathrm{~m}$., donde se instalan los cultivos de regadío y la labor intensiva de secano (principalmente 
cereales). Por encima, en altitud sólo encontramos cultivados los glacis que se sitúan en el piedemonte de la Cordillera Ibérica, ocupados por los viñedos del Campo de Cariñena y de La Almunia. Sólo dos pequeñas áreas superan los $1000 \mathrm{~m}$., cubieras por matorral o bosques de frondosas y/o coníferas.

Vamos a ver cuáles son los efectos que provoca el relicve sobre el clima en este área:

El enmarcamiento entre el Pirinco y la Cordillera lbérica que sufre el centro de la Depresión, incrementado por la presencia de plataformas terciarias (La Plana de Zaragoza, La Muela, Montes de Castejón, Sicrra de Alcubicrre), ejerce sobre el área un efecto de Cubela que estanca las masas de aire: en verano se recalienta, dando lugar a olas de calor; en invicmo favorece la pérdida de calor nocturna por irradiación, provocando heladas y nieblas matutinas con inversiones térmicas.

La disposición orográfica promucve el apantallamiento de los frentes asociados a Borrascas que penctran por el Norte y Oeste, descargando las nubes en barlovento y llegándonos un airc cálido y reseco, que acentúa los problemas de aridez.

Se forma un pasillo de dirección obligada para los vientos (NW-SE), convirtiendo los dos sentido de ella en las trayectorias dominantes de un viento que se enfila e incrementa la velocidad de sus rachas.

\section{EL CLIMA}

\section{Las precipitaciones}

La precipitación media del sector central de la Depresión del Ebro, entre 1970-1984, es de 379,1 mm., aunque con diferencias espaciales importantcs, desde los $452 \mathrm{~mm}$. de media en Cariñena, hasta los 313 recogidos en Zaragoza Aeropuerto. Lluvias que se reparten de forma muy desigual según los años, con una inclinación generalizada a duplicar los ciclos anuales húmedos la precipitación de los $\operatorname{secos}$ y manifestándose en el último quinquenio una acusada tendencia a la sequía.

Esta escasez e irregularidad interanual y la imposibilidad de contar con una disponibilidad hídrica más o menos fija para todos los años es una de las características más definitorias.

Mientras que un año seco cstá ocasionado por la existencia de un periodo sin precipitación prolongado, un año húmedo lo es por la presencia de uno o varios meses con volúmenes elevados de lluvias, que coinciden como veremos, con mayo, junio o septiembre, independientemente de que en ese mismo año pueda haber algún mes seco. Incluso en un mismo ciclo anual 
seco o húmedo pueden coexistir considerables diferencias intermensuales $\mathrm{e}$ interestacionales.

La distribución mensual de las precipitaciones muestra un máximo destacado en primavera, Mayo es el mes más lluvioso, con diferencia, en todos los observatorios, suponiendo alrededor del $15 \%$ de lo contabilizado en todo el año.

El mínimo es estival (Julio), acumulando precipitaciones medias inferiores a $20 \mathrm{~mm}$. y sucediéndose los periodos secos extraordinariamente largos durante el verano.

En agosto vuelve a aumentar el volumen total de precipitaciones obtenidas, pero dado que el estío es la época seca, a causa del predominio anticiclónico, es la frecuencia de tormentas veraniegas la que explica estos mayores volúmenes. Con ello, la precipitación estival supera a la invernal, excepto en Alagón, revelando el Matiz Continental de nuestra área de estudio, reforzado por el relieve circundante.

Este mínimo veraniego tiene importantes repercusiones agrícolas, pues a la exiguiidad del agua hemos de añadir las altas temperaturas alcanzadas.

Septiembre es un mes extraordinariamente variable, pudiendo ser fiel continuador de la sangría hídrica veraniega o verse afectado por tormentas a las que se responsabiliza de los totales más cuantiosos observados.

El máximo secundario aparece en Otoño, causado, como el de la primavera por el paso de perturbaciones asociadas al Frente Polar.

El Invierno es el mínimo secundario. Las temperaturas, más bajas, y una menor demanda hídrica disminuyen sus repercusiones.

A la vez hemos de destacar que en el centro de la comarca las precipitaciones son más escasas, aumentando conforme nos alejamos de él y ascendemos en altura.

El número de días en los que se totabiliza la lluvia muestra una distribución similar.

De su relación con los volúmenes de precipitaciones medias deducimos que las lluvias de primavera e invierno, repartidas en un número mayor de días, se corresponden con borrascas ligadas a perturbaciones frontales que originan más días de lluvias pero con volúmenes escasos de agua, cuando no inapreciables.

Las precipitaciones de verano son de tipo tormentoso, por lo que son más intensas, aunque repartidas en un menor número de días.

Las Iluvias de otoño participan en ocasiones de la torrencialidad veraniega, como en septiembre, o de la suavidad de las lluvias frontales del régimen invernal. 
Como ya hemos visto en el reparto mensual de las precipitaciones, el rasgo más destacado del cálculo de probabilidades de que la precipitación alcance y/o supere determinado volumen es la lrregularidad.

La diferencia intermensual vuclve a presentar la misma distribución, con un máximo primaveral y un mínimo estival.

Es interesante conocer estos datos para poder relacionarlos con las labores agrícolas sincrónicas a ellos, ya que es la primavera uno de los momentos de mayores exigencias hídricas.

A finales de marzo y principios de abril se necesita un suelo rico en humedad previo a la siembra de los cereales de primavera y para el buen desarrollo de los del invierno. Estas exigencias se prolongan durante el mes siguiente durante el encañado de los cereales. Lo mismo ocurre en el mes de octubre-noviembre.

Para los cultivos más exigentes en humedad nos acerca al conocimiento de la proporción de agua que podemos esperar y a las previsiones de ricgos hata completar su necesidad.

De las previsiones otoñales no podemos hacer una generalización, ya que las variaciones entre los distintos observatorios son muy fuertes, así como las cantidades alcanzadas según probabilidades. Esta irregularidad es el único común denominador de esta época. La probabilidad de que las lluvias sean insuficientes para cubrir las necesidades es alta, aunque puede suceder, ocasionalmente, que las precipitaciones sean voluminosas. El tiempo seco y soleado, en cambio, beneficia la vendimia y la recogida de frutos secos.

Es interesante conocer las previsiones que se pueden hacer a finales de noviembre y principios de diciembre, ya que, en el caso de un octubre sin lluvias, las que se producen en esta época suelen ser muy beneficiosas. Para toda la comarca son más abundantes en el tramo final del otoño que en el primero, en el que se prolonga la sequía veraniega, y que podemos considerar como parte de este periodo estival.

Las repercusiones agroclimáticas que manifiestan nos obligan a interesarnos, no sólo por los parámetros medios, sino por los valores extremos que estos meteoros pueden presentar.

Así, las precipitaciones máximas producidas en 24 horas se recogen con preferencia en las estaciones equinociales, generadas por las siguientes situaciones de tiempo:

a) en Primavera el paso de borrascas acompañadas de Embolsamientos de aire frío en altura y circulación ciclónica, sobre masas de aire con mayores temperaturas en superficie, consecuencia de la importante radiación solar.

b) en Otoño, con temperaturas aún altas, la aparición de este aire en capas supcriores de la atmósfera, más frío y húnedo crea la situación propicia para 
la inestabilidad formando las golas frías, que aparecen al estrangularse cstos embolsamientos. Estas gotas frías suelen ser las responsables de precipitaciones catastrólicas en otros puntos de la Península (Lcvante).

Los efectos de las precipitaciones máximas son diferentes según la ćpoca del año en que se producen y su extensión temporal.

En Primavera suponen un imporlante aportc hídrico. El suclo, en buenas condiciones de humedad pucde absorver mejor cl agua, más aprovechada en conjunto. Siendo un área con tantos problema hídricos, estos aportes resultan siempre beneficiosos. En áreas de secano pueden determinar la cuantía y calidad de las cosechas.

En Otoño, tras la sequía veraniega, el suclo no está tan acondicionado para empapar estas precipitaciones que, si se producen en una intensidad horaria fuerte, verán disminuida su eficacia, a pesar de seguir siendo beneficiosas, pues en septiembre se prolonga el déficit hídrico, sobre todo por las altas temperaturas, que no mitigan la cvapotranspiración.

Es importante asímismo la consideración de otros meteoros de importantes repercusiones agrícolas: las tormentas y el granizo, que consideramos aparte de las precipitaciones máximas en 24 horas, pues no siempre se presentan sincrónicamente.

El reparto de las tormentas es similar en todos los observatorios y coincide con la evolución de las temperaturas. A los valores térnicos más clevados se corresponde la probabilidad más alta de ocurrencia de este fenómeno.

El número de días de tormenta va ascendiendo gradualmente desde los meses de inviemo hasta alcanzar el máximo en julio y agosto. Se desarrollan generalmente por la tarde, con el viento en calma. El fucrte calentamiento a que se ven sometidas las masas de aire en contacto con la superficie terrestre provoca movimientos verticales y baja presión, dando origen a estas tormentas. La continentalidad que se acusa en Calatorao, en el valle del Jalón y la influencia de la Ibérica sobre Cariñena favorece la formación de tormentas, más abundantes y cuantiosas que en el resto del área, y es por ello que los volúmenes allí recogidos aumentan sensiblemente.

Son beneficiosas para la Agricultura en cuanto aportan recursos hídricos a un suclo que está muy necesitado de cllos, al estar casi agotada su reserva. Supone también la incorporación de nitrógeno al suclo, proporcionado al realizar la síntesis del oxígeno y del azoe.

Pero sus consecuencias puden ser funestas, no por la lluvias en sí, sino porque en ocasiones les acompañan el granizo y pedrisco, además de vientos fuertes y racheados.

El Granizo se presenta con más frecuencia en abril-mayo y en los meses de verano. En ambos momentos es peligroso, fundamentalmente para los 
productos hortofrutícolas, que están ya avanzados (floración-fruclificación c incluso maduración), con lo que se puede perder la cosecha o afectar sensiblemente a la calidad de los productos.

\section{Periodos secos}

Hemos visto cómo uno de los rasgos más característicos del régimen de precipitaciones de esta zona es su escasez c irregularidad en el reparto. La deficiencia hídrica se refuer'a cuando hacemos un estudio de periodos secos.

Llamamos Período Seco al comprendido entre dos días de precipitación apreciable, superior a $0,1 \mathrm{~mm}$. Los días de precipitación inapreciable, tan frecuentes en la comarca de Zaragoza, se consideran como secos, a no ser que se encuentren dentro de un periodo húmedo.

Los periodos secos de duración inferior a 5 días se repiten más en invierno, donde suponen entre el 57 y $67 \%$ del total de los invernales, lo que está en correspondencia con la mayor humedad relativa y la abundancia de nieblas. Los observamos con más frecuencia en Alagón. El número de días de lluvia es alto, pero son volúmencs de cscasa cuantía.

Por el contrario, en verano son muy cscasos, con un mínimo muy acusado en julio.

Periodos superiores a 15 dias nos hablan ya de una sequía prolongada, con mayores repercusiones agrícolas. Se presentan preferentemente en verano, aunque en Cariñena y Zaragoza "Acropuerto" son relativamente altos durante todo el año.

Sequías acusadas, superiores a los 30 días tienen consecuencias aún mayores, ya que se puede llegar a agolar la reserva del suelo cuando se presentan acompañadas de temperaturas altas $y$, por tanto, de fucrte evapotranspiración. Esta falta de agua supone una fuerte influencia sobre la agricultura ya que no sólo las temperaturas bajas pueden marcar el periodo de reposo de la actividad vegetativa, también es capaz de ello la escasez hídrica.

Cariñena es el observatorio más afectado por sequías tan prolongadas en el tiempo y el periodo del año en que más se repiten es el Verano. Están producidos por una situación Anticiclónica prolongada en el tiempo y, aunque en ocasiones recorran la Península perturbaciones, éstas no afectan a nuestra comarca. Un ejemplo de ello es 1978, donde se registró un periodo seco de 5 meses. En Fuentes de Ebro, entre el 31 de junio y el 2 de diciembre sólo hubo 3 días de precipitación.

Otra situación de tiempo característica de periodos secos cstá relacionada con el Efecto de Pantalla del que se responsabiliza al relicve circundante. Puede observarse el paso de sistemas frontales acomipañados de borrascas 
poco activas, con bajo gradiente de presión y sin vaguadas en altura que refuercen la actividad de los frentes cn superlicic. Estas masas de aire, cuando llegan sobre la vertical de nuestra comarca están ya resccas, por lo que no llegan a descargar, o si lo hacen es tan sólo de forma inapreciable.

Generalmente estos periodos secos sólo se ven interrumpidos por tormentas que dan las precipitaciones máximas en 24 horas en esta época.

Periodos secos tan largos son menos habituales durante la primavera, lo cual es un dato a tener en cuenta, pues las lluvias primaverales podrian salvar la cosecha. Pero no podemos dejamos llevar por las apariencias, pues, aunque las estadísticas afirmen este hecho, la experiencia de nuestros agricultores demuestra que pueden sucederse primaveras extremadamente secas, incluso después de otoños lluviosos, en las que los cereales de secano ni siquiera llegan a espigar.

\section{Eficacia de las precipitaciones}

Veamos cuál es la eficacia de las precipitaciones, fundamental para poder establecer una relación más real entre la climatología y la agricultura.

El aprovechamiento de las precipitaciones es diferente según la época del año en que se producen y su correspondencia con las labores agrícolas, la intensidad y volumen de las precipitaciones y si éstas se producen tras un periodo seco o húmedo

Hemos visto cómo las precipitaciones del centro del valle del Ebro sciı escasas e irregulares a lo largo del año.

Son más abundantes durante la Primavera, estando muy bien aprovechadas. Absorvidas por un suelo y unas plantas que están preparadas para ello, a las que resultan muy necesarias y beneficiosas. Las temperaturas aún no son muy elevadas, con lo que la evapotranspiración potencial es todavía menor que la disponibilidad hídrica (precipitaciones más reserva edáfica).

Las lluvias de Invierno también se aprovechan bien. No son volumirosas, pero están muy repartidas, con periodos secos que no sobrepasan los 15 días, además de que la demanda hídrica también es menor.

Las Veraniegas, generalmente tormentosas benefician, pues son prácticamente el único aporte de agua en esta estación, pero su carácter ocasional y su inmersión en un periodo seco, hace que no sean tan positivas como si estuvieran más repartidas en el ticmpo.

Frecuentemente, las situaciones que siguen a las lluvias propician la penetración de vientos del NW, fríos y desecantes, que aumentan la ETP y 
disminuyen su eficacia. Este fenómeno se ve agravado cuanto más aisladas y menos cuantiosas son estas precipitaciones.

Se produce con relativa facilidad cuando se observa circulación de vaguada y embolsamientos de aire en altura. Las lluvia, entonces, están casi aseguradas. la recupcración de la circulación zonal provoca la cnirada de vientos del NW.

Si las precipitaciones han sido poco cuantiosas, cl problema que causan supera con creces su potencial beneficiosidad. Las plantas han perdido sus defensas y el azote del viento las reseca y perjudica todavía más.

De la misma forma, la entrada de Bochorno (SE) después de las lluvias da lugar al aumento de las temperaturas máximas, manteniéndose las minimas. Cuando las lluvias han sido escasas, disminuye su eficacia por la aceleración de la ETP.

\section{La humedad atmosférica}

Su distribución a lo largo del año presenta una dinámica distinta a la de los volúmenes de precipitación. Alcanza sus valores máximos en el inviemo; además de que las tempcraturas son bajas y la ETP menor, son abundantes los días lluviosos.

EL mínimo estival establece una buena correspondencia con la sequía de esta época del año y precipitaciones muy concentradas en el ticmpo.

En otoño la humedad relativa es más alta que en primavera, pues en ćsta la temperatura, más alta , y la mayor frecuencia de vientos con velocidades medias altas, desecantes, elcvan la necesidad de evapotranspiración, disminuyendo la humedad ambiental.

\section{LA NIEBLA}

La niebla es uno de los meteoros que más afectan al centro de la Depresión del Ebro, favorecido por su disposición topográfica. Es un fenómeno de condensación en las capas bajas de la atmósfera, de gran extensión y poco espesor. Se asocia, en invierno, a situaciones de tiempo estables, anticiclónicas, con inversión térmica de la masa de aire en contacto con la superficie, de menor temperatura que las que están sobre ella.

Es frecuente de noviembre a febrero, si bien en los observatorios a menor altura y localizados más al centro, se prolonga hasta junio, como es el caso del acropuerto zaragozano, donde incluso se registran brumas en algunos días de verano. 
La proximidad del Ebro y de otros ejes lluviales como fuentes de humedad, aumentan la posibilidad de formación de estos bancos de nicblas. Por ello en Zaragoza es tan frecuente, principalmente en la confluencia de los ríos Ebro, Gállego y Hucrva. La descmbocadura del Gállego es un punto en el que se fija las nieblas. Unos metros más arriba, como cn Aula Dei, a pesar de su proximidad al Ebro y a las hucrtas, la nicbla ha podido levantarse o ni siquiera haberse formado.

En general, las situaciones anticiclónicas que las originan, con tiempo estable e irradiación nocturna, cstán acompañadas de una escasa amplitud térmica diaria y de heladas nocturnas.

Frena la actividad de la radiación solar. Por otra parte, la abundante humedad ambiental durante la noche aminora la pérdida de calor y evita, por tanto, las heladas de irradiación, a pesar de que las temperaturas alcanzadas sean bajas, incluso infcriorcs a $0^{\circ}$.

En algunos casos puede dar lugar a "heladas negras", muy temidas por los agricultores por los perjuicios que causan. Las gotas de agua que flotan en la atmósfera, con temperaturas muy bajas, pueden helarse al contacto con las plantas, pero no son frecuentes en nuestra área y, caso de aparecer, no duran muchos días.

Las situaciones de niebla no suclen ser perjudiciales para la agricultura. Sólo si se presentan muy tempranas pueden impedir una correcta aireación de la tierra previa a la siembra.

En alguna ocasión también pueden aparecer paralclas a las heladas tardías, con altas presiones y tiempo estable. Por esta circunstancia son más peligrosas, impiden la llegada de la radiación solar a la superficie y, por tanto, la acumulación de horas de calor.

Otros Meteoros, como el rocío y la escarcha aumentan el número de días de precipitación inapreciable. Se presentan con más frecuencia en las cercanías de las áreas de los productos hortofrutícolas. Su repcrcusión sobre los cultivos es, por tanto, la misma que la de las precipitaciones inapreciables.

La escarcha es más peligrosa. Sobre todo en días soleados con temperaturas bajas (próximas a $0^{\circ}$ ), pues a la salida del sol se evapora con rapidez robando calor a la planta y helando sus puntos más delicados.

\section{Las temperaturas}

La temperatura media anual del sector central de la Depresión del Ebro es

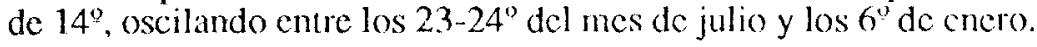


Su distribución a lo largo del año revela periodos lérmicos muy contrastados, con máximas elevadas en verano y mínimas acusadas en invicrno.

La dinámica de las temperaturas muestra un ascenso de los valores térmicos progresivo hasta marzo, mes en que cl gradiente sufre un incremento importante, que despućs se ralentiza hasta alcanzar el máximo. El descenso es más brusco.

Debido a ello, la amplitud térmica es muy alta, principalmente en Verano, como consecucncia del fucrte calentamiento solar. La continentalidad, reflejada en las temperaturas extremas está más representada en Calatorao, encajado en el valle del Jalón, y Cariñena, mientras que Zucra es el observatorio que tiene más mitigadas las diferencias de temperatura.

La característica térmica más sobresaliente de las estaciones equinociales es que la primavera y el otoño no representan el tránsito gradual desde el invierno al verano y viceversa, sino que suclen participar de las caractcrísticas de una de las dos, retrasando o adelantando el calor y el frío.

Desde el punto de vista térmico, el Pcríodo Crítico para la agricultura lo representa la primavera, pues a la misma vez que aumentan las temperaturas existe un riesgo paralelo de heladas tardías.

En la evolución de las temperaturas en relación con cl ciclo vegetativo podemos distinguir:

-periodo de reposo. A partir de octubre-noviembre, para ver cómo es la acomodación a las bajas temperaturas del periodo frío.

-periodo de actividad vegetativa. Con especial atención a las heladas primaverales, en el cambio de periodo.

\section{PERIODO DE REPOSO}

El otoño no constituye un "puente térmico" que permita la lenta adecuación de la vegetación al periodo de reposo. La entrada del invierno se produce sicmpre de forma brusca, ya sea por prolongación de las altas temperaturas en septiembre e incluso octubre o por la llegada temprana y repentina del frío.

En este último caso es interesante tener en cuenta que los fríos tempranos favorecen la floración en la primavera siguiente.

Emberger (1942) considera como periodo frío el compucsto por los meses con temperatura media de las mínimas inferior a $7^{\circ}$. Se corresponde con los meses de riesgo de heladas, y su duración se extiende entre novicmbre y abril en nuestra comarca. 
El origen de estas bajas temperaturas aparece ligado al predominio de situaciones anticiclónicas, con heladas de irradiación nocturna; o están provocadas por la invasión de aire ártico, procendente del $\mathrm{N}$, facilitando el acceso a masas de aire procedentes de Centroeuropa y Siberia. Son olas de frio.

La duración de este pcriodo frío se prolonga, en primavera, hasta abril. Pero desde los primeros días de Marzo, en muchas ocasiones, y desde la segunda mitad en prácticamente todos los años, las temperaturas aumentan y suele interrumpirse la parada invernal. A partir de dos o tres días con la media de las mínimas superior a $7^{\circ}$ se reinicia la actividad vegetativa. Por ello, las heladas posteriores a esta fecha están acompañadas de mayor repercusión agrícola. El periodo que se extiende desde que se despierta la actividad vegetativa (principios de marzo) hasta que desaparece totalmente el riesgo de heladas (mediados de abril) es el principal periodo crítico de la agricultura zaragozana.

La mayor parte de este tipo de heladas es de advección (masas de aire frío de $\mathrm{N} \circ \mathrm{NE}$ ), pero también pueden verse acompañadas por una fuerte irradición nocturna, en el caso de que un Anticiclón se apodere de la Península. Se caracterizan porque su descenso térmico es intenso y muy rápido.

\section{PERIODO DE ACTIVIDAD VEGETATIVA}

El periodo de actividad vegetativa se inicia cuando la temperatura mínima se sitúa por encima de los $7^{\circ}$ ( a menudo desde comienzos de marzo).

Periodo libre de heladas

Ya hemos indicado cómo la primavera no marcaba el carácter de tránsito entre el frío invernal y el calor del verano, y combina las altas temperaturas con las heladas tardías.

La reincorporación al periodo vegetativo y altas temperaturas no se realiza de forma paulatina sino acelarada el intensa. El gradiente de ascenso es fuerte.

Desde finales de mayo las temperaturas son elevadas y desde Junio a Septiembre hay un buen número de días con máximas superiores a $30^{\circ}$. Es el periodo cálido.

La Dirección General de la Producción Agraria considera periodo cálido aquel en que las altas temperaturas provocan una descompensación en la fisiología de la planta, o se produce la destrucción de alguno de sus tejidos o células. Su duración se reparte entre julio a agosto (t.m. alrededor de $30^{\circ}$ ). 
Las temperaturas máximas del periodo 1970-1984 supcran, con creces los $40^{\circ}$. (45 en Calatorao, 43 en Cariñena, $42,6^{\circ} \mathrm{cn} \mathrm{Z}$. Acropuerto, en julio de 1978,1978 y 1982 respectivamente).

Estas olas de calor se generan por influencia anticiclónica,con tiempo cstable, seco y soleado, o por el acceso de vientos deI $S$., resecos, que se recalientanen el interior peninsular. Esta masa de aire tropical arrastra polvo sahariano dando lugar a calimas.

El estancamiento de aire en la cubcla por bloqueo de la circulación zona provoca estas situaciones. Las altas temperaturas forman bajas superficiales que, en ocasiones, desembocan en tormentas, suavizando las temperaturas.

Los efectos negativos de estas temperaturas se ven incrementados por su coincidencia con periodos secos prolongados y humedad relativa ambiental y edáfica bajas. Incrementa la necesidad de cvapotranspiración.

\section{El viento}

El viento es un elemento del clima con gran signifiación agrícola, particularmentc, como veremos, en el valle del Ebro.

Modifica las temperaturas, regula la eficacia de las precipitaciones y suele ecelerar la evapotranspiración. Su importancia depende de la frecuencia, vclocidad y si se presenta en una dirección dominante o no.

El porcentaje de calmas en nuestra comarca es escaso (alrededor del 12\% en Zaragoza "Aeropuerto").

Se observa viento durante un alto número de días a lo largo del año, con dos direcciones dominantes:

$-\mathrm{NW}$, cierzo.

-S-SE, bochorno.

Esta dominancia la permite la configuración del relicve. La Depresión queda ubicada entre dos sistemas montañosos, macizos y de altura considerable: la Cordillera Ibérica y los Pirineos, formando un pasillo por el que discurren los vientos, acelerando su velocidad por este efecto. Las Muelas que enmarcan nuestra área todavía refuerzan más este efecto.

\section{EL CIERZO}

Es el flujo del NW, aunque vientos en origen del Norte u Oeste ven modificada su trayectoria por la topografía.

Es un viento frio en invierno y fresco en verano, que se caracteriza por su sequedad. 
Frecuente durante todo cl año, aunque con mayor incidencia durante la primavera, se presenta con velocidades muy allas, en un alto porcentaje de ocasiones superior a los $13 \mathrm{~km} / \mathrm{h}$.

Las velocidades más fuertes destacan darante la primavera y a finales de otoño y comienzos del invicrno. MARZO es el mes en el que las rachas superiores a $50 \mathrm{~km} / \mathrm{h}$ son más abundantes, justo cuando los clectos pueden resultar más perjudiciales.

Las rachas máximas, en Zaragoza "Acropucrı" supcran los $70 \mathrm{~km} / \mathrm{h}$ y son muy frecuentes las de 7()-90, llegando a alcanzar los $136 \mathrm{~km} / \mathrm{h}$, como en novicmbre de 1979.

La situación atmosférica que los ocasiona ha de manilestar una diferencia de presión entre una Alta en el Allàntico y una Baja en el Mediterráneo. Es el flujo que hace penetrar las borrascas dinámicas ligadas a las perturbaciones del Frente Polar y que llevan asociadas familias de frentes que provocan lluvias.

No sólo acompañan a los días de precipitación sino que, a menudo, después de ellos penetra en nuestra comarca disminuyendo la eficacia de estas lluvias, por el aumento de la evapotranspiración, al ser desecante. A su paso bajan las temperaturas.

\section{EL BOCHORNO}

Procedente del Mediterráneo es cálido y húmedo y acompaña muchos periodos de lluvias, además de fomentar la inestabilidad y los movimientos ascendentes.

Se presenta en situaciones interciclónicas, con bajo gradicnte de presión o con Bajas superficiales, con presiones más altas en el Atlántico que en el Mediterráneo.

Normalmente no son tan persistentes como las rachas procedentes del NW ni alcanzan su velocidad. Pueden verse interrumpidos por periodos de calma $\mathrm{c}$ incluso, al atardecer, por un flujo débil del NW que refresca el ambiente.

En este sector central de la Deprsión del Ebro, el viento, particularmente el cierzo, resulta, pues, por su velocidad, su frecuencia y dirección dominante, perjudicial para la agricultura, ocasionando problemas de lipo mecánico y fisiológicos : castiga a las planlas, acelera la cvapotranspiración, rescca los cultivos, multiplicando el efecto desecane al alacar a las plantas cuando ćstas están "licrnas", despućs de las lluvias, no preparadas para hacerles frente. 


\section{Balance hídrico}

Si todos los factores y clementos del clima son importantes en la relación de éste con la actividad agraria, lo que nos da la verdadera pauta de la conexión agroclimática es el conjunto de todos los clementos climáticos interrelacionados entre sí.

En el sccano, es el aporte hídrico el principal condicionante de los cultivos, mientras que en el regadío, donde podemos disponer de agua abundante durante todas las épocas del año, es la temperatura el factor regulador. Pcro aunque podamos destacar algunos, el total de los elementos, íntimamente unidos, interactúa sobre el medio agrícola.

Una buena medida de esta interrelación entre clementos climáticos la constituye el análisis de la Evapotranspiración. Para su cálculo teórico combinamos dos variables: temperaturas medias y precipitaciones, aunque existen otros muchos factores que la modifican:

-el viento, su frecuencia e intensidad,

-la evolución de las temperaturas extremas, sobre todo en verano, donde máximas elevadas-por olas de calor-la aumentan,

-la humedad relativa,

-los diferentes estados fènológicos.

La evapotranspiración potencial, es decir, la cantidad de agua que tcóricamente podría llegar a evapotranspirarse, es muy elevada, suponiendo alrededor del doble de la cantidad de agua recogida por precipitaciones $(770 \mathrm{~mm}$. de media para toda el área, siguiendo el modelo de Thornthwaite, aunque en realidad puede ser superior a estos valores) .

De Noviembre a Marzo, en lineas generales, al superar la precipitación a la ET potencial, el agua excedente se acumula en el reservorio edáfico. En la primavera, la utilización de esta reserva hídrica permite que exista suficiente agua para responder a las necesidades.

De Junio a Noviembre se prolonga el déficit hídrico, siendo muy acusado en el centro del verano (en los meses de julio y agosto necesitariamos alrededor de $200 \mathrm{~mm}$. más de los que se dispone).

El déficit puede llegar a ser mayor, por la alta velocidad del viento, que estimula la capacidad de evapotranspiración, a la misma vez que reduce, en ocasiones hasta el máximo, la humedad relativa.

En momentos puntuales del verano, la ET potencial también pude ser superior. El estancamiento de masas de aire y su calcntamiento excesivo lo ocasiona. Tampoco hay que olvidar el azote del viento en la canícula que, a pesar de disminur las temperaturas facilita la cvapotranspiración. 
Así, en la etapa de aclividad vegetativa de las plantas, las necesidades de cvapotranspiración son muy supcriores a la disponibilidad hídrica. La floración y fructificación, principalmente aumentan la demanda.

\section{EFECTOS DEL CLIMA SOBRF, LA AGRICULTURA}

Hasta ahora hemos visto cuál es la evolución de los elementos climáticos. Vamos ahora a relacionarlos con las labores agrícolas y con cl desarrollo de los productos cultivados:

-dada la escasez de precipitaciones en este área, el Secano cstá muy ligado a las cantidades de agua disponible, procedente de lluvias.

-el Regadío, que puede subsanar la falta de agua con facilidad, llevará una evolución paralcla a la de las temperaturas, pero sin olvidar el efecto benéfico que las precipitaciones le ejercen.

\section{El reposo invernal}

EL periodo invernal se extiende desde noviembre a principios de marzo, cuando las temperaturas alcanzan los 5-7\%. Sus comienzos, a finales del otoño, coinciden con la entrada en letargo de los frutales y algunos productos hortícolas, y con la siembra de los cereales de secano.

AL número de horas con temperaturas inferiores a los $7^{\circ}$ se le denomina Horas-Frio. Cada especie manifiesta unas necesidades concretas que, en el campo de Zaragoza se ven sobradamente cubiertas.

Así, las Temperaturas de Invicrno (noviembre a principios de marzo) no producen efectos negativos sobre la agricultura:

-ni por falta de reposo (temperaturas elevadas)

-ni por las temperaturas de heladas (temperaturas demasiado bajas)

Un invierno frío favorece el posterior desarrollo agrícola. A los Frutales las bajas temperaturas, seguidas de una primavera cálida les permite una mejor floración y fructificación. Es muy beneficioso también para los Cereales a cuyas raíces permite ahondar; en caso contrario, la brotación se produce en fechas demasiado tempranas.

El acondicionamiento del suelo para recibir el sembrado necesita, para presentar condiciones óptimas, la presencia de humedad en el suelo, entre octubre y noviembre. Es lo que los agricultores llaman "buen tempero". La probabilidad de obtener buenas condiciones de humcdad son muy escasas, tan sólo $\mathrm{cl} 25 \%$ de los años la siembra se realiza sobre un suelo preparado; en noviembre la precipitación es mayor. 
La mayor parte de las ocasiones en que el otoño se presenta seco viene acompañado, además, de altas temperaturas que mantienen clevado el nivel de la E.T. potencial. Además, no hemos de olvidar el azote del viento durante esta época, persistente y de alta velocidad.

Los años húmedos, por el contrario, suelen presentarse favorables a la siembra, lo que sucede en un reducido porcentaje de ocasiones. En Zaragoza "Acropuerto", sólo en un 50\% de los años se alcanza, en el mes de octubre, una precipitación de $15 \mathrm{~mm}$., y sólo cxiste un $10 \%$ de probabilidad de que el volumen registrado sea de $35 \mathrm{~mm}$. Las fichas hídricas nos indican cómo la acumulación de agua en el reservorio edafico sólo es posible a partir del mes de noviembre, que es cuando la precipitación supera a la evapotranspiración potencial.

\section{Final del periodo de reposo-comienzo de la actividad vegetativa}

Por las temperaturas mínimas que se registran en esta zona, el periodo frío se prolonga hasta abril, acumulándose en este mes un número importante de horas-frío (t.m $<7^{\circ}$ ), principalmente en los observatorios de Calatorao, en el valle del Jalón, y de Cariñena, al pie de la Ibérica, como ya hemos visto.

Pero el periodo vegetativo, en realidad, se inicia con anterioridad a la finalización de esta etapa del ciclo anual. Además de las hortalizas que se cultivan durante todo el año, los frutales comienzan el desborre de yemas y la floración en fechas más tempranas.

Algunos de los más frecuentes:

- el almendro, que se cultiva en secano, florece a finales de febreroprincipios de marzo.

-de los de regadío, el albaricoquero es el más temprano y el más tardío el manzano. Excepto este último, durante el mes de marzo florecen la mayor parte de las especies. Por ello, las temperaturas bajas, (heladas) suelen tener repercusiones muy negativas.

En Primavera, en el tránsito entre el final del periodo invernal y principios de la actividad vegetativa, suelen darse combinadas dos situaciones que caracterizan esta zona:

-temperaturas elevadas tempranas que aceleran la salida del reposo. Dos o tres días con la t. media de las mínimas superior a $7^{\circ}$, desde primeros de fcbrero, comienzan a interrumpir el reposo, cualquiera que sean las temperaturas alcanzadas durante el invierno.

Por el contrario, si el frío se prolonga, la floración se retarda. 
- heladas tardias una vez recupcrada la actividad agrícola.

Un ejemplo lo encontramos en los meses de marzo y abril de 1980 . Sc observaron temperaturas inferiores a $0^{\circ}$ los días $17,21,24 \mathrm{de}$ marzo y el $10 \mathrm{de}$ abril.

Ya en febrero se habían obscrvado valores térmicos altos: la máxima absoluta de ese mes es de $19^{\circ}$ en Alagón, 21,4 en Calatorao, $21^{\circ}$ en Aula Dei, $19,5^{\circ}$ en Zaragoza "Acropuerto", superiores a las normales para esa época del año.

La temperatura máxima es también, al menos, $1,5^{\circ}$ supcrior a la media mensual de todo el periodo, lo mismo que la temperatura media de las mínimas.

$\begin{array}{lcl}\text { FEBRERO } & \mathbf{t . m . 2}(\mathbf{1 9 8 0 )} & \mathbf{t . m . 9} \\ \text { ALAGON } & 5 & \mathbf{3}, 3 \\ \text { CALATORAO } & 4,9 & 2,3 \\ \text { AULA DEI } & 4 & 2,7 \\ \text { AEROPUERTO } & 5 & 3 \\ \text { ZUERA } & 2,9 & 2,2\end{array}$

En marzo, la temperatura media cs igual que la t. media de las máximas del pcriodo, o ligcramente superior.

La floración ya se ha iniciado, y en las especics más tempranas ha sido plena cuando se registra esa temperatura

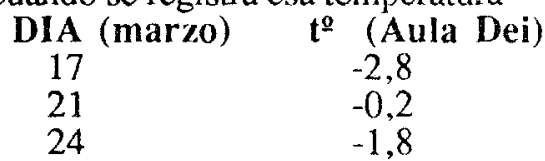

Afectaron a los melocotoneros, cuya floración se había producido en la primera y segunda decena de marzo, al ciruelo curopeo, al albaricoquero. Los daños alcanzaron, en la Estación Experimental de Aula Dei, al 50-90\% de las plantaciones de estos frutales.

En abril vuelven a registrarse temperaturas inferiores a $0^{\circ}$. Afectaron a otras especies más tardías.

Los efectos de estas heladas tardías se han estudiado principalmente en frutales:

* las yemas de flor son las partes más delicadas. Con las heladas tardías la floración ya se ha producido; en algunos casos ha sido plena, con lo que puede necrosar y cacr. 
* si se ha producido el cuajado del fruto, los daños dependen de la intensidad del frío. Cuanto mayor es el tamaño del fruto, menos perjudicial resulla.

* la susceptibilidad a las heladas varía en los distintos estados fenológicos: la yema de flor es menos resistente que la flor abierta, y ćsta, a su vez, meos que el fruto ya cuajado. Por ello, las heladas más perjudiciales son las que se producen en la última decena de marzo y primera semana de abril, que coincide con la floración de la mayor parte de las especies.

* cuando el frío es poco intenso, afecta a la epidermis, produciendo manchas de color pardo.

* en cualquier caso, las heladas afectan a la calidad, aspecto y composición de las cosechas.

Hemos de tener en cuenta también que en esta época es frecuente el azote del Viento, con rachas de velocidad alta, que contribuirá a incrementar los perjuicios sobre los productos hortofruticolas.

\section{La actividad regetativa}

Durante ella se suceden varios estados fenológicos: comienza con las floración de los frutales, a la que siguen la fructificación y maduración.

La espigazón de los cereales cs más tardía, lo mismo que su maduración, hasta la siega.

La actividad vegetativa se asimila al periodo libre de heladas, desde mediados de abril hasta primeros de noviembre.

Lafloración depende, fundamentalmente, de las temperaturas. Aunque cada especie y variedad tienen unos valores térmicos límite, en general, el intervalo propicio para ella oscila cntre 6 y $25^{\circ}$, con óptimos específicos.

En nuestra comarca, generalmente, los inviernos registran mínimas bajas desde fechas tempranas y a lo largo de él, y las primaveras suelen presentarse templadas, con lo que la floración es rápida y se desarrolla correctamente (independientemente de la aparición de heladas tardías ). Por el contrario, y menos frecuente, un otoño suave con temperaturas poco bajas en invierno y una primavera fresca la retrasan.

Si las horas de frío ya están acumuladas, a finales de febrero, si las temperaluras lo permiten, puede comenzar el desborre de yemas.

No obstante, hay otros factores que influyen en la duración de la floración, no sólo las tempcraturas:

- Insolación, que conviene que sca alta 
- no es favorable que haya Precipilaciones muy abundantes pues suclen afcctar al cuajado de los frutos, aunque tampoco conviene que scan demasiado escasas. Resultan muy beneficiosas en el periodo de crecimiento

- el Viento influyc negativamente. Además de sus efectos mecánicos, impide la polinización y fecundación correclas.

Las circunstancias climáticas más favorables para el periodo de floración son:

*t. máximas entre 15 y $25^{\circ}$

*ambiente moderadamente húmedo (60-70\% de humedad relativa)

* tiempo solcado

* viento en calma

En nuestra comarca las temperaturas son propicias a la floración, pero el ambiente es seco y el viento demasiado fucrte.

Vamos a ver el caso concreto de la floración de frutales, en la estación de Aula Dei, en el año agrícola de 1984-1985.

Este año, comparado con la media, del periodo 1970-1984, sufrió algunas variaciones:

* el albaricoquero, ciruclo, pera y cerczo florecieron en los mismos días que la media.

* el melocotonero retrasó sus flores unos 5 días, a causa de las mínimas bajas de los últimos días de febrero y primeras decenas de marzo (las mínimas bajas sólo afectan al melocotoncro).

* en el manzano se adelantó, aunque fue posterior a la última helada.

Aunque las máximas anteriores a la floración fueron sinilares a las medias, las de finales de marzo y principios de abril fueron algo superiores, lo que adelantó los ciclos fenológicos de esta especie

A mitad y finales de marzo se produjeron heladas tardías, una vez iniciada la floración (excepto en el manzano), e incluso habiéndose sobrepasado la plena. Pero, a pesar de que un alto porcentaje de ycmas de flor se vieron afectadas (sobre todo por la de los últimos días de mes), las temperaturas bajas apenas afectaron a la producción.

Durante la espigazón, los cercales necesitan abundante agua (abril-mayo para los cereales de secano). Coincide con la época más lluviosa del año, por lo que la probabilidad de que se cubran las necesidades medias es alta.

Las lluvias, abundantes en primavera, suelen salvar las cosechas, en caso de que el otoño-invierno haya sido seco. Pero aunque esta época recoja suliciente agua, si la primavera tienen déficil hídrico en exceso, la espigazón puede no llegar a producirse. 
Pero a pesar de ser la lluvia el factor nás importante, no podemos olvidar la íntima conexión que existe cntre ésta y el resto de los elementos climáticos: temperatura, vicnto, humedad relativa.

La evaluación de un experimento realizado con mezclas pratenses en la estación experimental de Aula Dei lo demuestra:

Durante la primavera de 1970:

-se recogicron $47,2 \mathrm{~mm}$., de febrero a mayo

-las temperaturas fucron muy bajas $\left(-8^{\circ}\right.$ en marzo)

-el cierzo, con rachas superiores a los $80 \mathrm{~km} / \mathrm{h}$. contribuyó a que la sequedad fucra mayor.

El resultado, en 1970, fue que mucha scmilla ni siquiera germinó y las plantas que llegaron a emerger perecieron.

La sequía no sólo puede disminuir la produccción, sino que puede tener otros efectos. En suelos abundantes en carbonato cálcico, como son los de nuestra área, se pueden formar costras "per ascensum".

\section{Crecimiento vegetativo, maduración y recolección}

Como sucede en los demás estados fenológicos, en este ciclo el comportamiento de cada especie va ligado a unas temperaturas, entre otros factores, que le son propias.

En los frutales son las que se registran durante el crecimicnto hasta que los cultivos están maduros.

Como ejemplo significativo analizaremos los periodos de maduración de frutales, en la campaña agrícola de 1984-85 en la Estación Experimental de Aula Dei.

Como había sucedido durante la floración, aunque algunas especies maduraron en sus fechas medias, hubo otras modificaciones.

Las temperaturas máximas del periodo de crecimiento $\left(27,5^{\circ}\right)$ fueron más altas que la media $\left(26,8^{\circ}\right)$ y así, mientras que el albaricoquero y melocotonero, más exigentes en calor, redujeron el periodo de floraciónmaduración, el peral y alguna variedad de ciruelo retrasaron la maduración, como consecuencia.

A los cerezos, de floración tardía y maduración temprana, no les afectó.

Las temperaturas elevadas, (olas de calor) durante el periodo de curecimiento sí que influyen negativamente, sobre todo a la calidad de los productos.

Los $30^{\circ}$ se alcanzan con frecuencia durante el verano, además de estar, generalmente, inmersos en periodos secos prolongados, con hunedad relativa muy baja. En ocasiones se observan, en esta época central del verano, rachas 
fuertes de vientos que, si suavizan las temperaluras, producen efectos negativos mecánicos y fisiológicos:

Las altas temperaturas provocan una disminución de la actividad fotosintética. A partir de los 32-36, cotidianos en el sector central del estío, en nuestra árca, se puede producir la Parada Vegetativa, frenando el crecimiento.

Los frutales, sobre todo a partir de la maduración o "envero", son muy sensibles al calor. Temperaturas superiores a $40^{\circ}$ producen la deshidratación y ablandamiento.

Si las olas de calor coinciden con la maduración, se puede ocasionar la caída de la fruta. En cualquier caso afectan a la calidad de la fruta y a su capacidad de conservación.

Las temperaturas altas $\mathrm{e}$ insolación abundante son beneficiosas para la maduración del cereal, que necesita tiempo seco para su recolección.

Pero cuando estos valores térmicos se extreman durante el periodo de crecimiento (olas de calor) sí que afectan negativamente, sobre todo a la calidad de los productos hortofrulícolas.

\section{CONCLUSIONES}

Vemos, pues, cómo la comarca de Zaragoza presenta unas condiciones climáticas que le son propias y que la convierten en un área particularmente crítica para el desarrollo agrícola:

-en primer lugar destacan las Heladas Tardías que afectan a la cantidad, calidad y aspecto de las coscchas.

-la Escasez e Irregularidad de las precipitaciones, que confiere a los secanos zaragozanos condiciones extremas de cultivo.

-el Cierzo, persistente y de alta velocidad, que disninuye la eficacia de las precipitaciones, es un agente desecante que multiplica el déficit hídrico y tiene importantes efectos mecánicos y fisiológicos sobre las plantas.

\section{BIBLIOGRAFIA}

ASCASO LIRIA,A; CASALS MARCEN,M: 1981. "Periodos secos y sequias en la Depresión central del Ebro". Geographicalia n¹1-12. Institución "Fermando el Católico".C.S.I.C. Zaragoza.

CUADRATS PRATS,J.M.: 1986. "La Agroclimatología aragonesa: aspecios condicionantes del secano y del regadio". El Sistema Agrario A ragonés. Institución Fcrnando el Católico".C.S.I.C. Zaragoza. 
ELIAS CASTILLO: 1963. Precipitaciones máximas en España. Régimen de intensidad y frecuencias. Madrid.

ELIAS CASTILLO; RUIZ BELTRAN: 1977. Agroclimatología de España. I.N.I.A. Madrid.

ELIAS CASTILLO; RUIZ BELTRAN: 1982. Estudio agroclimático de la provincia de Navarra. Institulo Navarro del Suclo. Pamplona.

HERNANDEZ NAVARRO ,M.L.: Agroclimatología de Zaragoza. Inst. "Fernando el Católico". Zaragoza (cn prensa)

TABUENCA, M.C.: 1965. Influencia del clima en plantaciones frutales. C.S.I.C. Estación Experimental de Aula Dei, Boletín n 8. Zaragoza.

TABUENCA,M.C.: 1985. "Temperaluras y pluviometría. Resumen del periodo 1954-1985. Observatorio de Aula Dei". Ann.Est. Exp. Aula Dei.n17 (3/4).pp.278-301.

I.N.M. Boletín Meteoroloógico Diario. 1970-1984. Ministerio de Transportes y Comunicaciones. Madrid. 


\section{Esquema topográfico de la "COMARCA DE ZARAGOZA"}

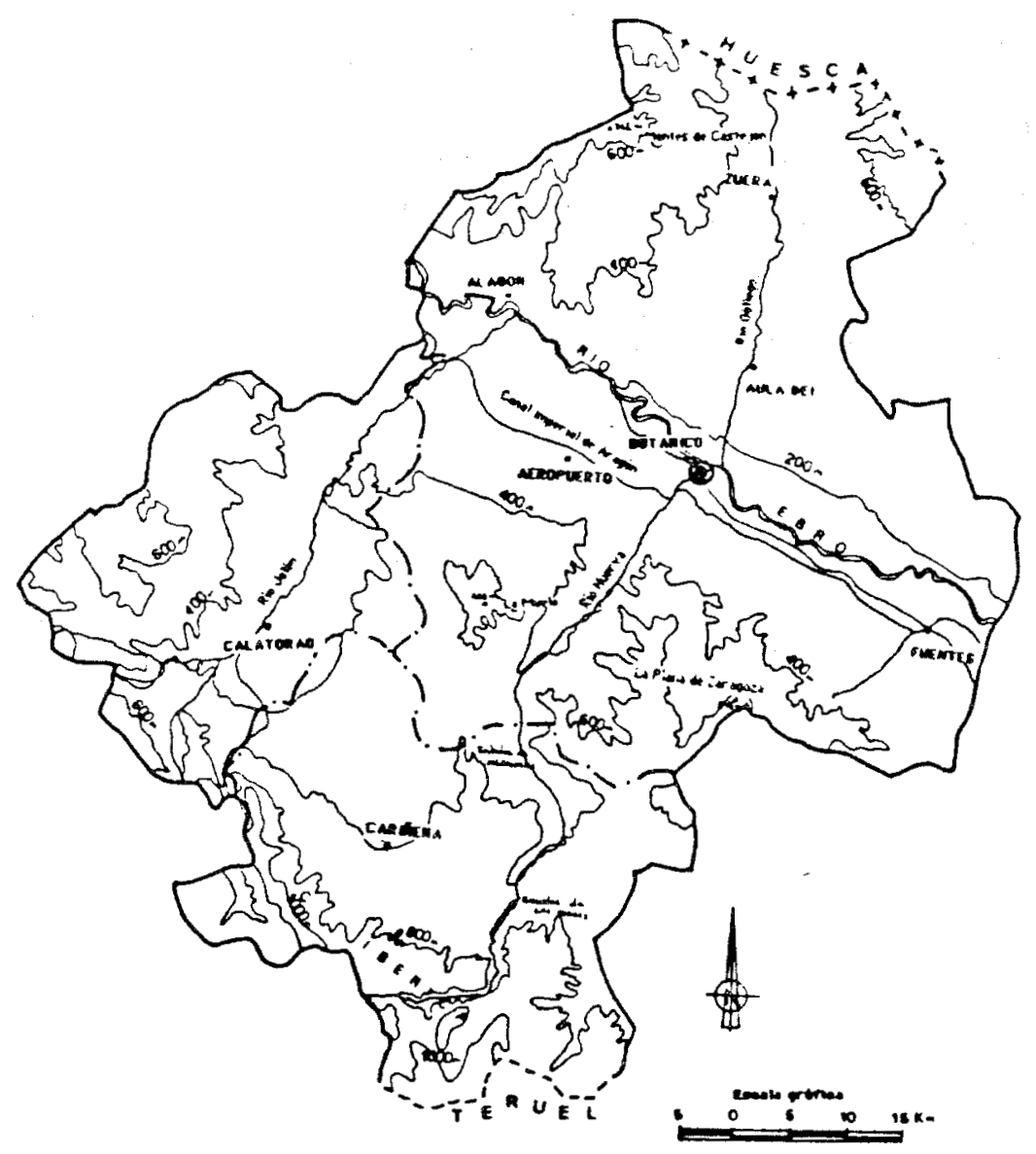


Precipitaciones medias mensuales
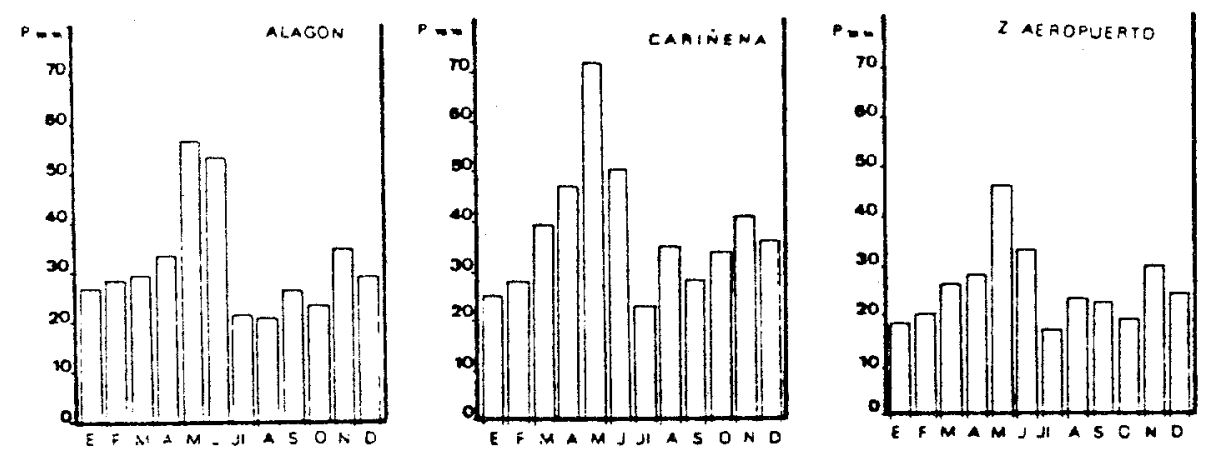

FRECUEMCIA, EN $\boldsymbol{x}$, DE FECHAS DE ULTIMA HELADA POSTERIOR aL 15 DE MARZD

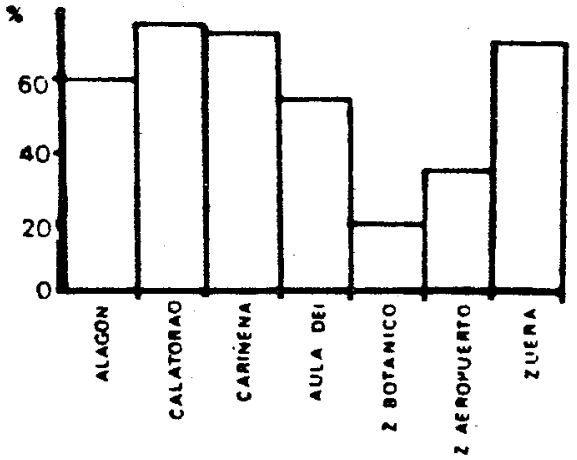

foente: SMK Centro Meteor elógico tel EMro

Elabor acibn prepia 
Probabilidad, en $\boldsymbol{R}$, de que la precipitación alcance y/o supere un volumen determinado.
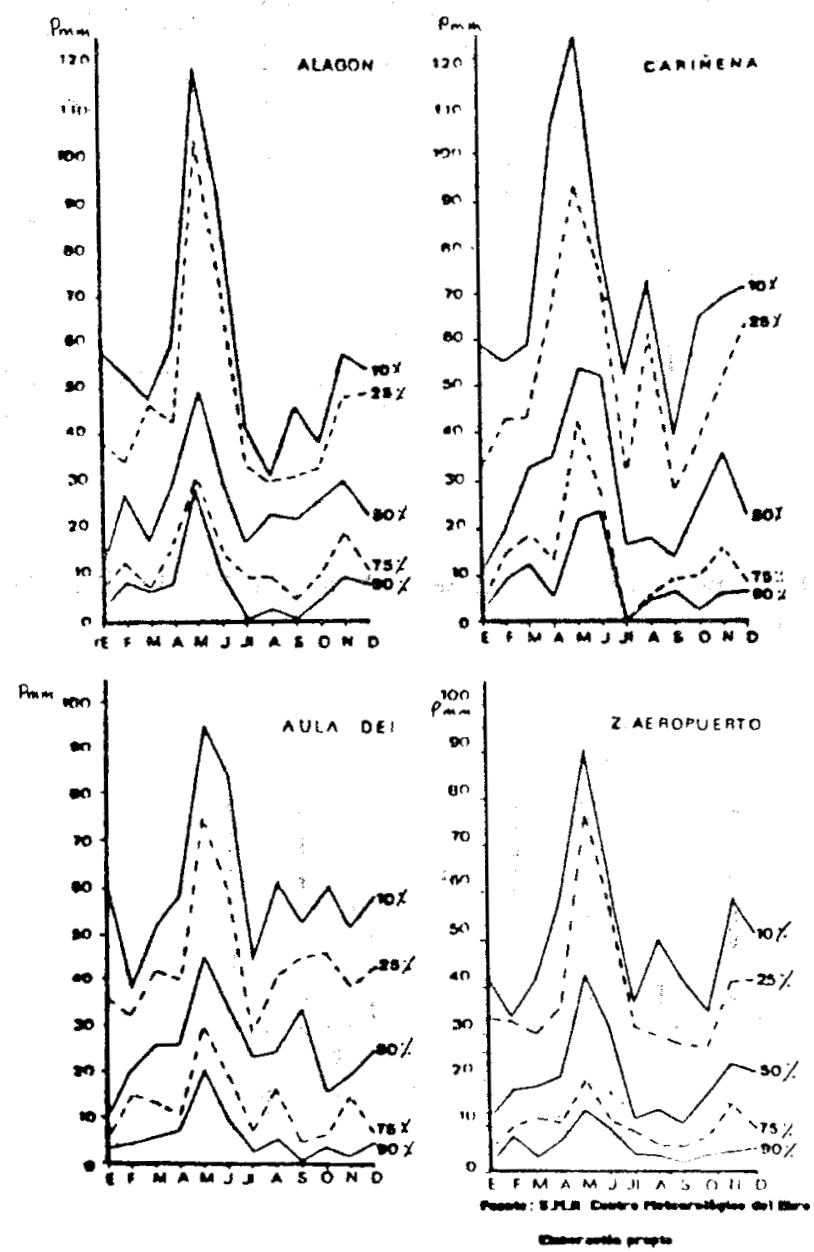


\section{Ficha hidrica}
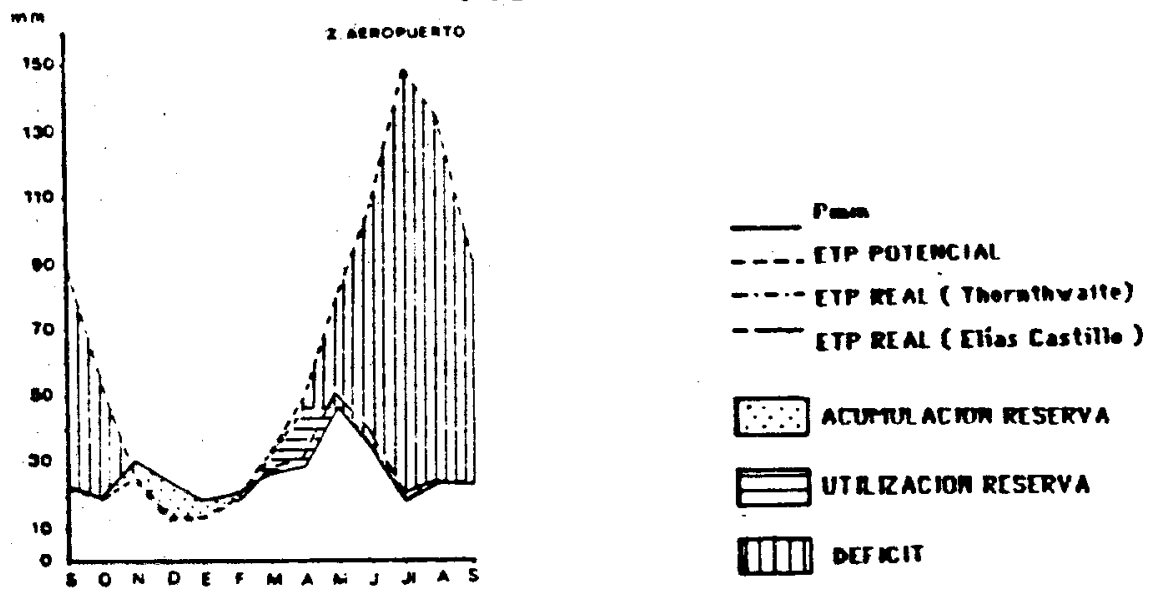

$\because \because$ acurrer ACKON RESERYA

Eutrracion restrva

Dill oxricis

\section{Temperaturas medias mensuales}
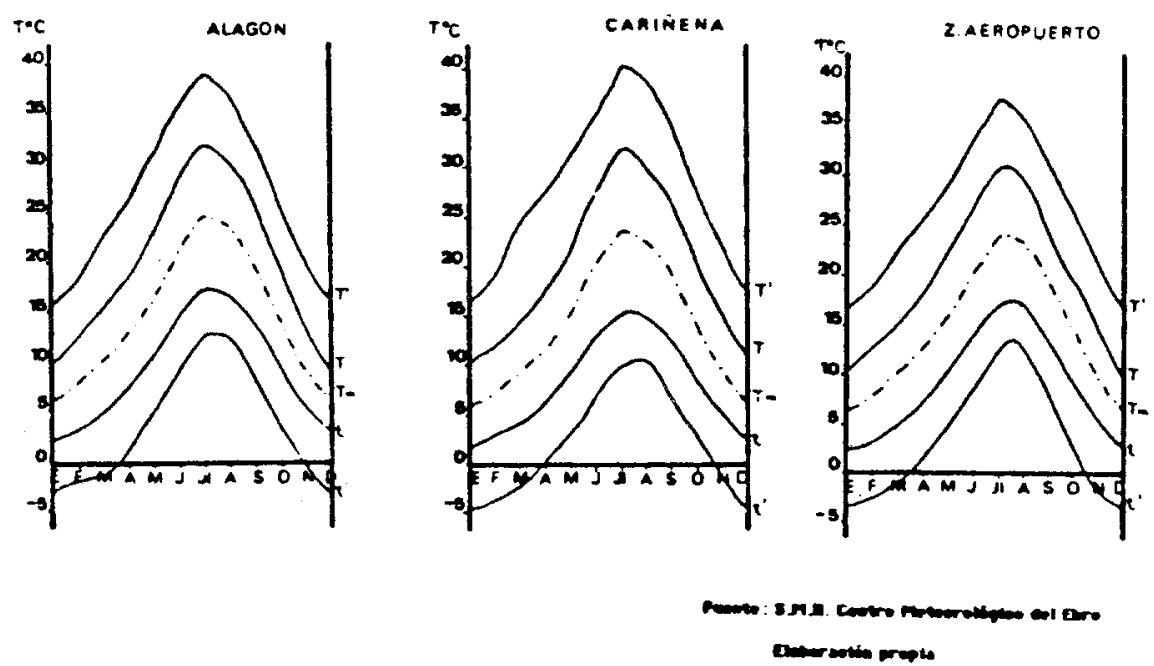


\section{Velocidad del viento, en $x$}

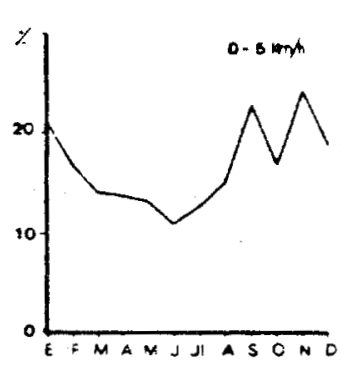

Z. AEROPUER TO
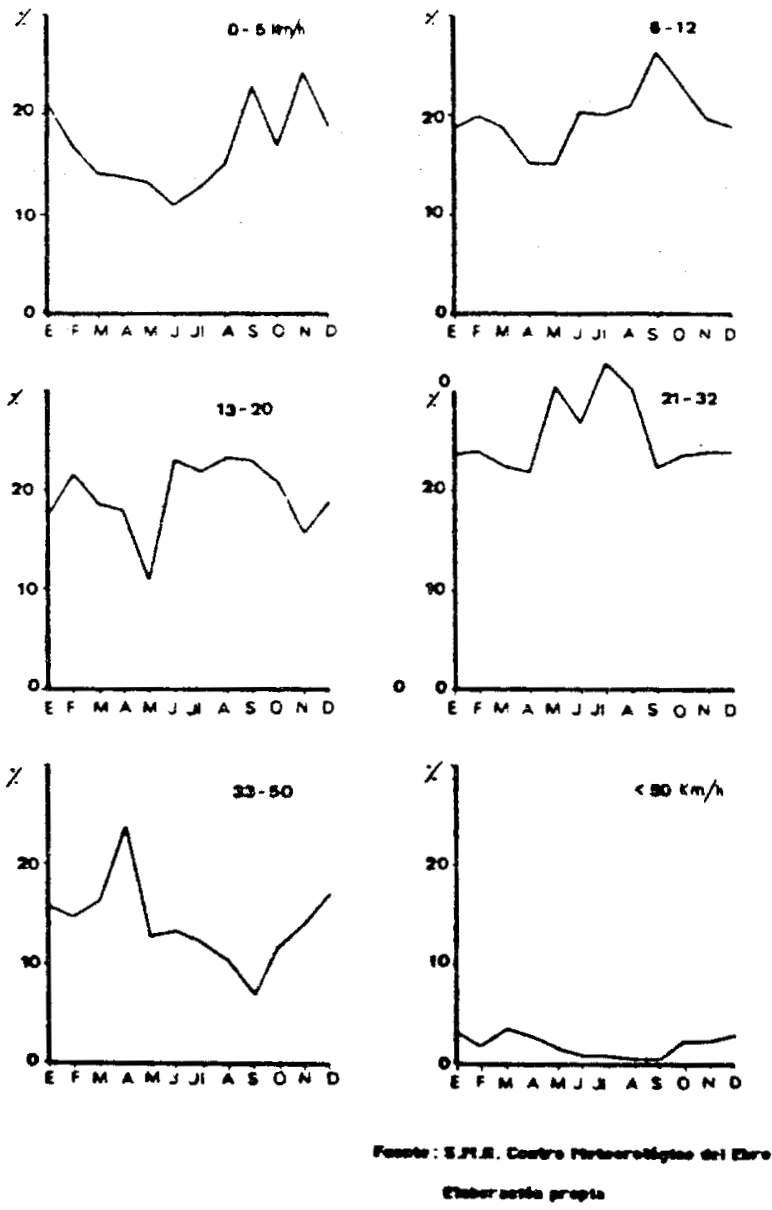


\section{Rosas climatológicas de vientos}

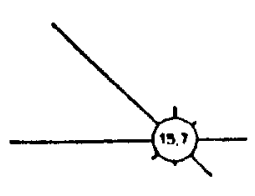

ENE NO

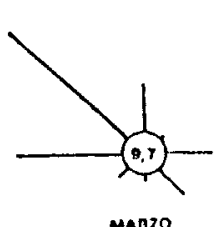

manzo

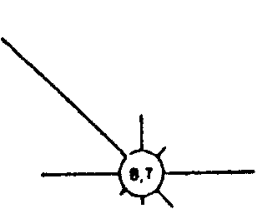

maYo

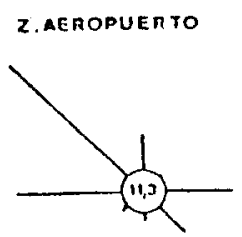

feOAERO
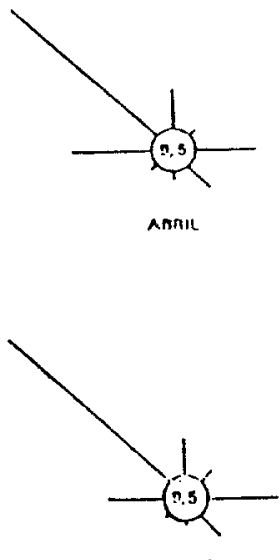

SUN1O

Lente praties

$0 \quad 2000 x$

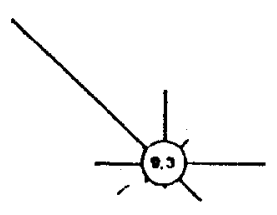

nuto
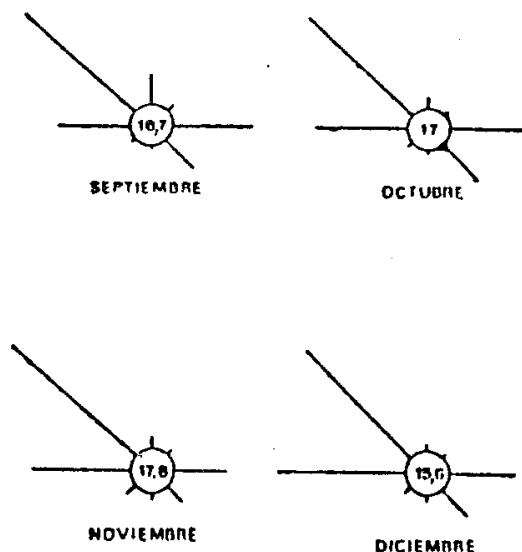

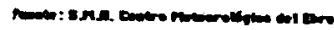

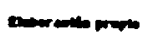




\section{Epocas de floración y maduracion de algunas especies frutales en relación con la climatologia}

\section{FLORACION}

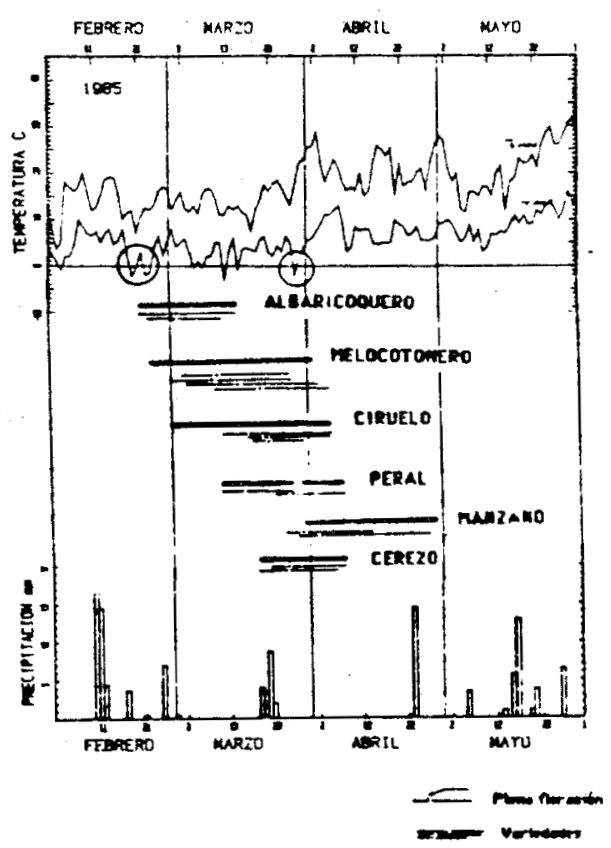

MADURACION

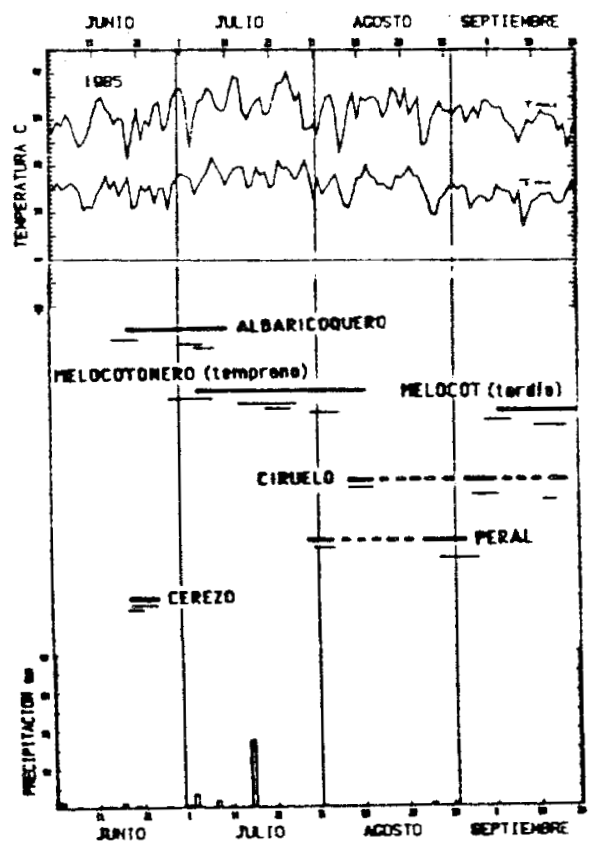

Adaptado de TABUENCA, M.C. (1985): "Factores climatológicos en la proouccion frutal: 1 octubre 1984-30 septiembre 1985".

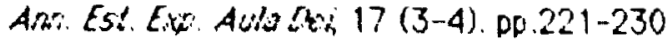

